\title{
Free Airtime for Grandma, the Materials Engineer
}

"Look around you. Everything that wasn't created by God, was created by engineers."

This was the message of a billboard I passed on a journey to Pennsylvania. It was also one of the few visible paeans to engineering I had ever seen. That noble and omnipresent profession is invisible to most people. This fact was brought home to me in a series of focus groups run by ASTRA (the Alliance for Science and Technology Research in America), in which the participants were asked to name a scientist or engineer. The only names the participants could come up with were scientists, specifically, very dead scientists-most of whom had passed from the intellectual landscape hundreds of years ago. But, more poignantly, not a single engineer was named. Apparently, even dead engineers have no status.

When I described this state of affairs to a friend of mine, he commented, "Well, you know that the only engineer on primetime TV is Homer Simpson." (For those of you who do not consume American TV,

Homer Simpson is a comedic buffoon on a cartoon series. He also happens to be a nuclear engineer.)

Into this sad but all-too-usual state of affairs comes a new program offered by the American Association of Engineering Societies (AAES): Voices of Innovation or VoI. This program takes engineeringinterest stories and weaves them into two-minute radio spots that play on over 60 affiliate stations across the United States and, via Voice of America, around the world. Each day brings a new engineering marvel or curiosity to the listen-

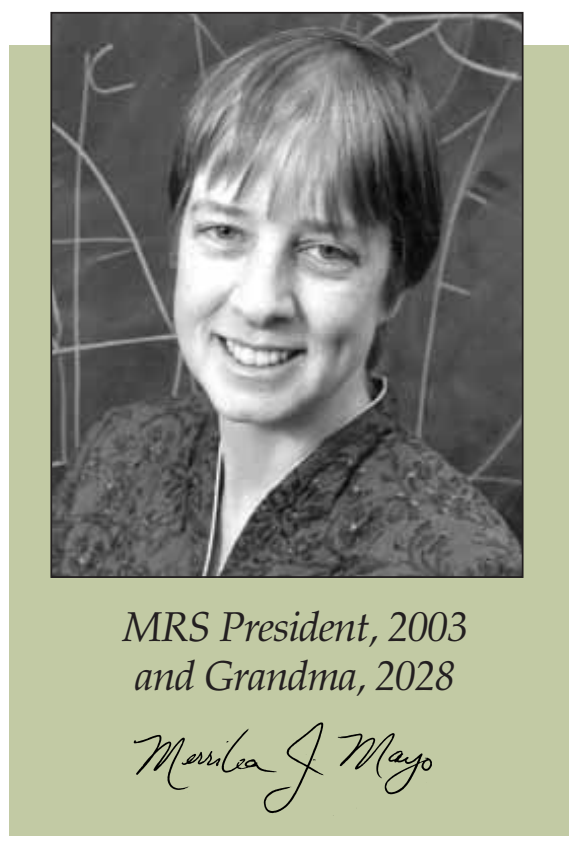

er. In January 2003, the series covered the high-strength metals used for gears in processing nylon, the evolution of "tin" (actually, tin-plated steel) cans from their wrought-iron roots, the engineering of fire-protection systems in buildings, the use of electrical engineering to reroute neural impulses, the analytical tools used by forensic engineers to solve crimes, the relationship between traffic engineering and driver behavior, and a whole series on how quick-thinking engineers delivered life-saving air to miners trapped in a mine shaft rapidly filling with water, as happened in the Que Creek mine in Pennsylvania in July 2002.

Remarkably, this free public-service radio series can be tapped by any scientist or engineer with a story to tell. It is a marvelous way to advertise a principal investigator's research work to the public, and in so doing, gain some visibility for one's academic department, research center, company, or government laboratory.

The procedure for getting a story on the air is remarkably easy. First, the ideagenerator fills out his or her contact information on the VoI Web site, www. voiceofinnovation.org/idea/, along with a paragraph for the story idea and contact information for the individual who should be interviewed for the story (who can be the same as the idea-generator). Upon receiving this information, the VoI team arranges the requisite interviews (sometimes by phone, sometimes in person, traveling to location as need be); professionally edits, mixes, and inserts voice-overs for the final product; and finally, disseminates the polished radio spot to $\mathrm{VoI}$ radio affiliates. The cost to idea-generators and interviewees is free, since the program is completely underwritten by AAES.

After the airdate, the final audio products can also be found and played right off one of the VoI Web pages, www. voicesofinnovation.org/archives/. The two-minute nuggets sit on the Web site in perpetuity, waiting for your grandchildren to log in and hear about "my grand$\mathrm{ma}$, the materials engineer."

Merrilea J. Mayo 2003 MRS President

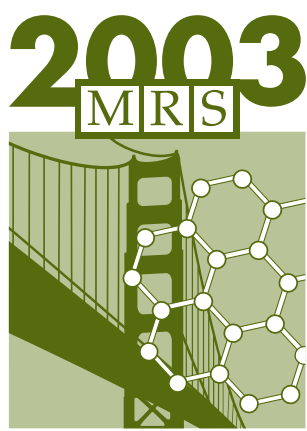

SPRING MEETING

April 21-25 • San Francisco, CA

\section{Attention MRS Members}

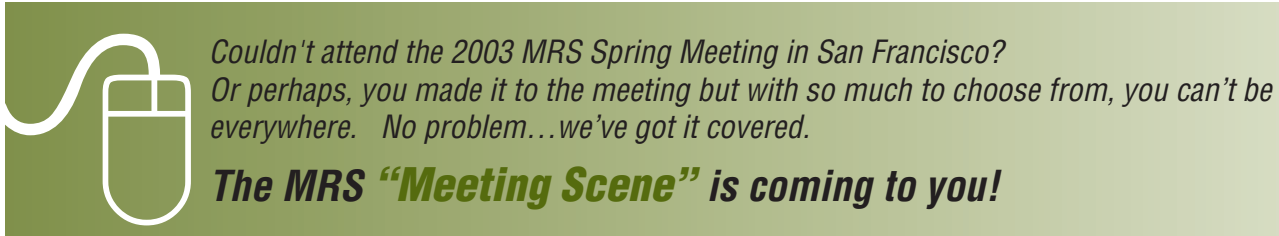

Check your e-mail daily from April 22-25. We'll be sending you news and highlights from the preceding day with links back to the meeting Web site. The Plenary and awards sessions. Symposium X talks. Poster award winners. The most exciting technical talks. And so much more.

Back by Popular Demand! The Meeting Scene... bringing you the very best of MRS. 